\title{
The Importance of Including Co-Factor Information when Reporting Resting Heart Rate
}

John Hart

Sherman College of Chiropractic, jhartdc@yahoo.com

Follow this and additional works at: https://nsuworks.nova.edu/ijahsp

Part of the Alternative and Complementary Medicine Commons, and the Analytical, Diagnostic and Therapeutic Techniques and Equipment Commons

\section{Recommended Citation}

Hart J. The Importance of Including Co-Factor Information when Reporting Resting Heart Rate. The Internet Journal of Allied Health Sciences and Practice. 2016 Jan 01;14(2), Article 1.

This Manuscript is brought to you for free and open access by the College of Health Care Sciences at NSUWorks. It has been accepted for inclusion in Internet Journal of Allied Health Sciences and Practice by an authorized editor of NSUWorks. For more information, please contact nsuworks@nova.edu. 


\title{
The Importance of Including Co-Factor Information when Reporting Resting Heart Rate
}

\begin{abstract}
Resting heart rate, sometimes referred to as resting pulse rate (RPR) is taken for various reasons in the various health care professions. As with many physiological tests, there are a number of basic factors that can affect RPR, such as gender and position of the patient during measurement. In most papers, these basic factors are included but in some they are not. If such information is lacking, the meaningfulness of the reported RPR is diminished. The purpose of this manuscript is to highlight the importance of including such information when reporting on RPR data.
\end{abstract}

\section{Author Bio(s)}

John Hart, DC, MHSc, is the Assistant Director of Research at Sherman College of Chiropractic in Spartanburg, South Carolina. 


\title{
TIAHSP \\ The Internet Joưnal of Allied Health Sciences and Practice \\ Dedicated to allied health professional practice and education \\ Vol. 14 No. 2 ISSN 1540-580X \\ The Importance of Including Co-Factor Information When Reporting On Resting Heart Rate: A Commentary
}

\author{
John Hart, DC, MHSC \\ Sherman College of Chiropractic \\ United States
}

\begin{abstract}
Resting heart rate, sometimes referred to as resting pulse rate (RPR) is taken for various reasons in the various health care professions. As with many physiological tests, there are a number of basic factors that can affect RPR, such as gender and position of the patient during measurement. In most papers, these basic factors are included but in some they are not. If such information is lacking, the meaningfulness of the reported RPR is diminished. The purpose of this manuscript is to highlight the importance of including such information when reporting on RPR data.
\end{abstract}

\section{Introduction}

Resting heart rate, also known as resting pulse rate (RPR) when obtained by palpation at a peripheral pulse, is a user-friendly method to assess, among other things, neurological health of the patient. Thus, one application of RPR is that it is potentially useful in determining whether the chiropractic patient needs a spinal adjustment for the purpose of improving neurological function. ${ }^{1}$ Nurses use RPR for a baseline measure as well as to monitor RPR changes that may occur later under care. ${ }^{2}$ Physicians have similar applications for RPR, and for them, a call for its increased use has been made:

"Although most doctors intuitively consider faster HR as an ominous prognostic sign, and take a slow HR to indicate a lesser likelihood of angina and/or a correct -blocker dosage, few manage HR as a risk factor on a par with cholesterol, blood pressure, etc., checking it regularly, titrating specific treatment, and monitoring long-term response. Yet HR is simplicity itself to measure, from the pulse or electrocardiogram, and is available at every visit." ${ }^{3}$

RPR is neurologically-based and supported by outcomes research that shows higher RPR is associated with worse outcomes compared to lower RPR. ${ }^{4-10}$ RPR literature also shows what its normative data is, not only by age, but by race and gender. ${ }^{11} \mathrm{As}$ is the case with many physiological tests, RPR is influenced by these (and other) co-factors. Thus, it is important that such information on these factors be included when reporting RPR data so the data can be more meaningful to readers. While most research papers on RPR include information on its co-factors, some do not include one or more basic factors. As an example, for patient position during measurement, in an otherwise excellent paper on resting heart rate and mortality, the position of the patient was not reported. ${ }^{4}$ This is problematic because the supine position (a common patient position for RPR) tends to result in lower RPR compared to seated (another common patient position for RPR). ${ }^{12,13}$ In another otherwise excellent paper, it is stated that blood pressure was taken in the seated position but did not specifically mention the position for resting heart rate. ${ }^{14}$ One might infer that the heart rate was also taken in the sitting position, but why not mention the position for both tests for purposes of clarity? In this particular study, it may not be readily assumed that the position was the same for both tests (blood pressure and heart rate) because they were tested with separate methods (semi-automatic cuff for blood pressure and ECG for heart rate). ${ }^{14}$ Omitting such information makes it difficult to compare reported RPR between papers.

The present commentary stresses the importance of including information for readers regarding basic co-factors when reporting RPR data. The commentary also takes reported normative data to the next level by statistically analyzing it to see if differences within the factors (e.g., male versus female) are statistically significant. Such analysis will help determine the importance of including information on the co-factors when reporting RPR data. 


\section{Methods}

Six co-factors from the literature: 1) age, 2) gender, 3) race, 4) count method (for manually-derived RPR), 5) position of patient during measurement, and 6) acclimation (pre-test rest) time were examined. These factors are self-explanatory except perhaps for count method, the rationale for which is provided as follows: When performing RPR, counting the first beat as 1 shows better agreement with ECG-generated heart rate versus counting the first beat as zero, even when using a count time as short as 15 seconds. ${ }^{15}$

Statistical calculations were performed for differences of age, gender and race based on reported RPR means, using various statistical programs, depending on the test and ease of the program. ${ }^{11}$ The normative data used were for the U.S. and reported on three races (white, black, and Mexican) and 12 age groups (<1, 1, 2-3, 4-5, 6-8, 9-11, 12-15, 16-19, 20-39, 40-59, 60-79, and $80+) .{ }^{11}$ These RPR measurements were taken with a) a stethoscope for those ages 4 and younger; and at the radial artery for those 5 and older; b) participants in the seated position after approximately 4 minutes of seated rest; and c) 30 second count time and then multiplied by 2 to achieve the numerical value in beats per minute (BPM). Among the co-factors analyzed in the present commentary, this report omitted information only about the count method. ${ }^{11}$

Each age category had six groups, two genders for three races, and each revealed satisfactory normal probability plots. Consequently, $\mathrm{t}$ tests were considered appropriate for these data, comparing two age groups at-a-time (e.g., age $<1$ versus age 1, age 1 versus ages 2-3, and so on) in Excel 2010 (Microsoft Corp., Redmond, WA).

For gender, both had an $n$ of 12 (for each age group), e.g., white male versus white female for each of the 12 age groups. Each of these six cohorts (white male, white female; black male, black female; and Mexican male, Mexican female) exhibited non-normality of data according to normal probability plots. Since the shape of six histograms was the same (right tail skew), the Wilcoxon test for matched pairs was performed, in InStat 3.0 (GraphPad, San Diego, CA).

For race, two ANOVA tests were performed, in InStat: 1) white, black, and Mexican males; and 2) white, black, and Mexican females. Here, the nonparametric assessment, the Friedman test was used for repeated measures ANOVA ( $n=12$ age groups per race-gender cohort).

Analysis for the co-factors of count method and patient position relied on reports where data were more summarily reported (e.g., one mean). ${ }^{12-13,15}$ The two studies used for patient position included all the co-factors analyzed in this commentary except for race. ${ }^{12-13}$ The study used for count method included co-factors of age and gender but omitted co-factors of race, patient position, and acclimation time. ${ }^{15}$ For these two co-factors (of count method and patient position), a calculator for the two sample t-test was used in Stata IC 12.1 (StataCorp, College Station, TX) where distribution of normality was assumed.

Acclimation time is typically reported in studies on resting heart rate, but sometimes it is not. ${ }^{16}$ For this co-factor, a recentlypublished study (by the author) was used. All co-factors analyzed in this commentary were included in this study except for race. ${ }^{17}$

For all analyses, two-tailed p-values of 0.05 or less were considered statistically significant.

\section{Continued on next page}




\section{RESULTS}

Age

Table 1: RPR means for the 12 age groups. The RPRs decreased among the 12 age groups to around the 40 to 59 age group. ${ }^{11}$ Paired t-tests, where each row (age group) is compared to its neighboring row below it (by age group), revealed differences that were statistically significant down to and including the 16-19 age group. $W F=$ white female. $W M=$ white male. $B F=$ black female. $\mathrm{BM}=$ black male. $\mathrm{MF}=$ Mexican female. $\mathrm{MM}=$ Mexican male. RPR means reported in BPM.

\begin{tabular}{|c|c|c|c|c|c|c|c|}
\hline Age & WF & WM & BF & BM & MF & MM & p \\
\hline$<1$ & 131 & 128 & 130 & 129 & 129 & 128 & \\
\hline 1 & 120 & 117 & 117 & 115 & 119 & 117 & $<0.0001$ \\
\hline $2-3$ & 109 & 106 & 107 & 103 & 107 & 104 & $<0.0001$ \\
\hline $4-5$ & 97 & 94 & 95 & 92 & 97 & 95 & $<0.0001$ \\
\hline $6-8$ & 89 & 86 & 87 & 83 & 88 & 87 & $<0.0001$ \\
\hline $9-11$ & 86 & 80 & 82 & 78 & 86 & 82 & 0.0009 \\
\hline $12-15$ & 81 & 78 & 78 & 72 & 79 & 76 & 0.0010 \\
\hline $16-19$ & 79 & 73 & 77 & 67 & 77 & 72 & 0.0064 \\
\hline $20-39$ & 76 & 71 & 76 & 69 & 75 & 70 & 0.1212 \\
\hline $40-59$ & 73 & 71 & 74 & 70 & 73 & 70 & 0.1747 \\
\hline $60-79$ & 73 & 69 & 74 & 72 & 73 & 70 & 1.0 \\
\hline $80+$ & 73 & 71 & 72 & 68 & 75 & 66 & 0.4150 \\
\hline
\end{tabular}

\section{Gender}

Table 2: Median average RPR differences reported in BPM; difference is female minus male. There were 12 age groups per comparison. ${ }^{11}$

\begin{tabular}{|c|c|c|c|c|}
\hline Race & Male & Female & Difference & $\mathbf{p}$ \\
\hline White & 79.0 & 83.5 & 3.5 & 0.0005 \\
\hline Black & 75.0 & 80.0 & 5.0 & 0.0005 \\
\hline Mexican & 79.0 & 82.5 & 3.5 & 0.0005 \\
\hline
\end{tabular}

\section{Race}

Table 3: Comparison of median average RPR reported in BPM using repeated measures ANOVA for the three race groups by gender with 12 age groups. Variation was statistically significant among the female race groups $(p=0.0390)$ as well as male race groups $(p=0.0456)$.

\begin{tabular}{|c|c|c|c|c|}
\hline Gender & White & Black & Mexican & p-value \\
\hline Males & 79.0 & 75.0 & 79.0 & 0.0456 \\
\hline Females & 83.5 & 80.0 & 82.5 & 0.0390 \\
\hline
\end{tabular}

\section{Count Method}

As an example, counting from 0 using a 30 second count time resulted in a $1.72 \mathrm{BPM}(\mathrm{SD}=2.89)$ absolute difference from ECG versus $0.44 \mathrm{BPM}(\mathrm{SD}=2.12)$ difference when using 1 as the first counted beat. The difference of these differences was $1.28 \mathrm{BPM}$ (standard error [SE] 0.25) and statistically significant $(p<0.0001)$.

\section{Position of Patient}

Differences between seated and supine RPR were greater in younger versus older persons. Netea et al found an RPR increase of $1.5 \mathrm{BPM}(\mathrm{SE} 0.3)$, that was statistically significant $(p<0.001)$ was observed from supine-to-seated positions. ${ }^{13}$ Frey et al. found the RPR increases from supine to seated were 7.2 BPM for males $(n=22)$ and 3.5 BPM for females $(n=25) .{ }^{12}$ P-values for these 
positional differences in this latter study (after converting SE to SD) were statistically significant for males $(p=0.0062)$ but not for females $(p=0.2877)$.

\section{Acclimation Time}

Thirty chiropractic students (18 female, 13 male; ages 21-54 years old) had their RPR measurements taken in the seated position with a 30 second count, beginning with a count of "1," using the following acclimation (pre-test rest) times, also in the seated position: 1, 3, 5, 7, and 9 minutes. RPR was compared by acclimation time. Statistically significant differences were observed in comparisons involving the 1 versus 3 minute acclimated readings $(p<0.05$, but not when 5,7 , and 9 minute acclimated readings were compared with each other $(p>0.05)$.

\section{Discussion}

Based on these results, these six factors (age, gender, race, count method, position of the patient, and acclimation time) at a minimum should be taken into account and mentioned when RPR measurements are reported. Obviously, there are other factors that can influence heart rate (e.g., certain medications) and should also be accounted for and reported. The factors analyzed in this commentary can be easily determined / known by the clinician. Many papers on heart rate do include these factors but some do not, including, admittedly, one by the author used in the present commentary (where the variable of race was omitted). ${ }^{17}$ Other factors that could be included in papers, not addressed thus far in this manuscript, include the following:

a) Position of the patient during the pre-test rest period. It may be intuitive to assume that the position during pre-test rest and measurement would be the same, but why not mention the position for both activities (pre-test rest and measurement) for purposes of clarity?

b) Length of time for measurement (e.g., 30 second count versus 60 second count for manual RPR). This factor relates to the count method (beginning with 1 versus zero) when comparing (manually-derived) RPR to ECG (less agreement with shorter count times, especially when first beat is counted as zero instead of 1)..$^{15}$

c) Method of measurement (e.g., ECG versus manually-derived RPR). This may be only a minor point since ECG and (manually-derived) RPR tend to have good agreement, particularly when the RPR count begins with 1 instead of zero for the first counted beat. ${ }^{15}$

The most common factors omitted when RPR is reported, from this author's perspective, are: a) position of the patient during measurement, b) pre-test rest time and position during the rest time, and c) RPR reported by race. As another example from the literature, resting heart rate normative data reported from the Framingham study thankfully included information on position of the patient during measurement (supine), method of measurement (ECG), and provided the heart rates by age group and gender. ${ }^{18}$ What this reader would have liked to also see included in this otherwise very informative paper is information on pre-test rest time (and position for this rest) as well as a breakdown of RPR by race.

\section{Conclusion}

Basic factors that can influence resting heart rate measurement should be included when reporting resting heart rates. These factors could minimally include the patient's age, gender, race, count method, patient position, and acclimation time. Whether in practice or research, including this information will give additional context and meaning to report rates for resting heart rate.

\section{REFERENCES}

1. Hart J. Resting pulse rate as a potentially useful autonomic marker for neurologically-based chiropractic practice. The Internet Journal of Chiropractic. 2013;2(1). DOI: 10.5580/2ccc. http://ispub.com/lJCH/2/1/14450\#

2. Mensink GBM, Hoffmeister $\mathrm{H}$. The relationship between resting heart rate and all-cause, cardiovascular and cancer mortality. Eur Heart J. 1997;18:1404-10. [PMID: 9458445]

3. Verrier RL, Tan A. Heart rate, autonomic markers, and cardiac mortality. Heart Rhythm. 2009;6(11 Suppl):S68-75. [PMID: 19880076] 
4. Hsia J, Larson JC, Ockene JK, Sarto GE, Allison MA, Hendrix SL, Robinson JG, LaCroix AZ, Manson JE. Resting heart rate as a low tech predictor of coronary events in women: prospective cohort study. British Med J. 2009;338:577-80. [PMID: 19193613]

5. Greenland P, Daviglus ML, Dyer AR, Liu K, Huang CF, Goldberger JJ, Stamler J. Resting heart rate is a risk factor for cardiovascular and noncardiovascular mortality. Amer J Epidemiol. 1999;149:853-62. [PMID: 10221322]

6. Jouven X, Empana JP, Escolano S, Buyck JF, Tafflet M, Desnos M, Ducimetiere P. Relation of heart rate at rest and long term (> 20 years) death rate in initially healthy middle-aged men. Amer J Cardiol. 2009;103:279-83. [PMID: 19121452]

7. Migliaro ER, Contreras P, Bech S, Etxagibel A, Castro M, Ricca R, Vicente K. Relative influence of age, resting heart rate and sedentary life style in short-term analysis of heart rate variability. Brazilian J Med Biol Res. 2001;34:493-500. [PMID: 11285461]

8. Skills - taking the pulse. Nursing Times. Accessed on May 22, 2015 at: http://www.nursingtimes.net/nursingpractice/clinical-zones/cardiology/skills-taking-the-pulse/205603.article

9. Alegria E. To what extent has monitoring of heart rate reduction in your coronary patients become part of your daily practice? Medicographia. 2009;31(4):395.

10. Nauman J, Janszky I, Vatten LJ, Wisloff U. Temporal changes in resting heart rate and deaths from ischemic heart disease. J Amer Med Assoc. 2011;306:2579-87. [PMID: 22187277]

11. Ostchega $Y$, Porter KS, Hughes J, Dillon CF, Nwankwo T. Resting pulse rate reference data for children, adolescents, and adults: United States, 1999-2008. National Vital Statistics Rep. 2011;41:1-16. [PMID: 21905522]

12. Frey MA, Tomaselli CM, Hoffler WG. Cardiovascular responses to postural changes: Differences with age for women and men. J Clin Pharmacol. 1994;34(5):394-402. [PMID: 8089251]

13. Netea RT, Smits $P$, Lenders J, Thien T. Does it matter whether blood pressure measurements are taken with subjects sitting or supine? J Hypertens. 1998;16:263-8. [PMID: 9557918]

14. Reunanen A, Karjalainen J, Ristola P, Heliovaara M, Knekt P, Aromaa A. Heart rate and mortality. Journal of Internal Medicine. 2000;247:231-9. [PMID: 10692086]

15. Hwu YJ, Coates VE, Lin FY. A study of the effectiveness of different measuring times and counting methods of human radial pulse rates. J Clin Nurs. 2000;9:146-152. [PMID: 11022503]

16. Diaz A, Bourassa MG, Guertin MC, Tardif JC. Long-term prognostic value of resting heart rate in patients with suspected or proven coronary artery disease. Eur Heart J. 2005;26:967-74. [PMID: 15774493]

17. Hart J. Short-term stability of resting pulse rates in chiropractic students. Journal of Chiropractic Medicine 2015; 14 (3): 162-168. [PMID: 26778929]

18. Kannel WB, Kannel C, Paffenbarger RS, Cupples A. Heart rate and cardiovascular mortality: The Framingham Study. Am Heart J. 1987;113(6):1489-94. [PMID: 3591616] 